
www.globaljournalseries.com, Email: info@globaljournalseries.com

\title{
PERSONAL CHARACTERISTICS AND COMPLIANCE TO HEALTH EDUCATION AMONG PREGNANT WOMEN ATTENDING ANTENATAL CLINIC IN UNIVERSITY OF CALABAR TEACHING HOSPITAL, NIGERIA
}

\author{
R. E. ELLA, E. E. ESIENUMOH AND I. N. OJONG \\ (Received 17 July 2017; Revision Accepted 30 August 2017)
}

\begin{abstract}
This study investigated personal characteristics (individual factors) associated with compliance to health education among pregnant women attending antenatal clinic in University of Calabar Teaching Hospital, (UCTH) Calabar, and Cross River State, Nigeria. Level of Knowledge, educational status, age, parity and time' of pregnant women were isolated and examined. Three research questions and one hypothesis were formulated to guide the study. Literature was conceptually, empirically and theoretically reviewed based on the variables under study. Descriptive design was adopted, and using the convenience sampling technique, a sample size of 140 pregnant women who attended antenatal care from May 2016 to November 2016 was used. A validated and reliability certified (with a correlation coefficient of 0.79) structured questionnaire was used to generate data from respondents. Questionnaire was administered through face to face interaction and on the spot collection of completed questionnaire. Data were presented using frequency tables, pie-charts and bar-chart, while chi-square $\left(X^{2}\right)$ analysis at 0.05 level of significance was used to test the hypothesis. The results of the study showed that individual factors that facilitated compliance were level of knowledge and level of education of the pregnant women; $72.9 \%$ of the study participants had adequate knowledge about health education and a greater proportion $(62.9 \%)$ complied with health education. Chi-square analysis of the hypothesis showed a statistically significant association between level of education and compliance towards health education $\left(X^{2}\right.$ cal $=31.56, X^{2}$ crit $\left.=7.815, P=0.05, d f=3\right)$. Number of children (parity) and lack of time were the individual factors that hindered compliance. It was therefore recommended that Midwives should intensify efforts in awareness creation on family planning and its benefits, to reduce number of children to give mothers time to take care of themselves. Government of Nigeria and Cross River State in particular should reduce the high cost of education thereby encouraging every citizen to have basic education thus reduce illiteracy level of women and of its citizens in general.
\end{abstract}

KEYWORDS: Pregnant women, Antenatal Care Services, Individual factors

\section{INTRODUCTION}

Non compliance to health education during Antennal Care (ANC) is an underlying factor in more than $50 \%$ of the major causes of maternal mortality. Million more women survive but suffer from illness and disability related to pregnancy and childbirth (Abosse, Woldie \& Ololo, 2010). Antenatal care (ANC) period presents opportunities for reaching pregnant women with health education to maximize maternal health during and after pregnancy and the health of their neonates. ANC is an important period of contact between health workers and pregnant women for provision of health education. Antenatal Care services involves a careful systematic assessment and follow up of pregnant women in health education, counselling, screening and treatment to ensure best possible health of the mother and foetus (Al-Ateeq and Al-Rusaiess 2015). The principles of ANC for women with uncomplicated pregnancies are to provide education, reassure, and support; to address and treat the minor problems of pregnancy; and to provide effective screening during the pregnancy (Dhange, Breeze, and Kean, 2013). Health education is one of the major aims of antenatal care. Health education during ANC covers good nutrition, exercise, clothing and travel during pregnancy; avoidance of malaria, sexually transmitted infections (STIs)/Human immunodeficiency virus (HIV) and Acquired immune deficiency syndrome (AIDS), and danger signs of pregnancy (Dhange, Breeze \& Kean,2013).

The term compliance describes the ability to act according to an order, set of rules or request. It is an act of complying which has the tendency of conforming with or agreeing to the wishes of others. In the present context compliance refers to the accuracy with which a pregnant woman follows an agreed plan of health education given to her during ANC by the midwife. However, pregnant women personal characteristics such as knowledge, understanding, time factor, age, parity, and level of education can affect their compliance to health education during ANC. Compliance to health

R. E. Ella, Department of Nursing Science, Faculty of Allied Medical Sciences, University of Calabar, Calabar, Nigeria.

E. E. Esienumoh, Department of Nursing Science, Faculty of Allied Medical Sciences, University of Calabar, Calabar, Nigeria.

I. N. Ojong, Department of Nursing Science, Faculty of Allied Medical Sciences, University of Calabar, Calabar, Nigeria. 
education among pregnant women reduces risk of maternal complications and death; foetal disease with resultant death while non compliance on the other is one of the major causes of maternal and foetal death among pregnant women. Nigeria's current maternal mortality ratio (MMR) is 814 maternal deaths per 100,000 live births (CIA World Fact book 2016). According to Nwosu et al (2012), 42\% of MMR is associated with non compliance to health education during antenatal care, whereas compliance leads to the reduction of mortality rate and ensures good health of mother and baby.

Compliance is a dynamic process which varies continuously, and relatively is low (65\%) in developing countries when compared to developed countries which is $97 \%$ ( Pell, Menaca, Were, Afrah, Chatio, Manda-Taylor, et al 2013). Initiation and complete attendance of ANC by pregnant women facilitates compliance. Survey data from Sub-Saharan Africa indicates that women only initiate ANC after the first trimester and do not achieve the recommended number of visits (Pell, Menaca, Were, et al 2013). Also maternal mortality ratio (MMR) still remains high in Sub Saharan Africa and indeed Nigeria despite substantial reduction global trends in maternal deaths UNECF (2013), UNFPA (2012). For example, in Nigeria, MMR rose from 545 to 575 deaths per 100,000 live births between 2008 and 2013 pointing that the fifth MDG was not being achieved as should be (NPC 2014). Nwosu, Urama \& Uruakpa (2012), Dario and Owoyokun, (2010) argued that in Nigeria compliance to health education by pregnant women is still low, and the non compliance varies from region to region and from state to state with its resultant perculiar complications. Several studies conducted on pregnant women compliance to health education during ANC are in relation to economic status, cultural practices and family support. Very few had explored in detail pregnant women personal characteristics such as parity, age, level of education and time factor, and how these affect their compliance. Again, in Nigeria compliance of pregnant women to health education during ANC is not uniform within the State, LGA's or town. There are variations due to religious beliefs, ethnicity, socioeconomic and demographic strata. Despite these variations the negative effect of poor or non compliance cut across the various groups. This fact justifies the need for regional studies that allow for more efficient action in regard to measures for intervention based on locality. This study therefore seeks to investigate pregnant women personal characteristics on their compliance to health education during ANC in University of Calabar Teaching Hospital, Cross River State, Nigeria.

Some research studies have shown that individual factors (personal characteristics) of pregnant women such as Knowledge, level of education,, age, parity , time factor, and understanding guide compliance (Onyenecho et al 2013, Ojong, Uga \& Chiotu 2015; Akah, Emeribe \& Edem, 2013). For instance, in a cross sectional study on factors associated with compliance to recommended micro nutrients during pregnancy in South east Nigeria conducted by Onyenecho, Aromu, Chukwu, Wodikeizu, Chaluwsposki and Subramanian (2016) the result showed that some personal characteristics showed significant association with compliance.

\section{Knowledge Level of Pregnant Women and Compliance}

Knowledge is a vital aspect in compliance; it involves the understanding of relevant information in a clear concise manner. Knowledge also implies being aware, and before a pregnant woman can comply with health education, she must be aware of the benefits of the ANC services and consequences of not complying. Health education is about raising pregnant women's health awareness and working with them to encourage compliance. Mersal, Esmat and Khalil (2013) intervention study, conducted to evaluate the effect of prenatal counselling on knowledge and compliance with health promotion in teenage pregnancy and pregnancy outcomes at Elkhosos, a village in El-Kalubia Governorate, Egypt revealed that, at the post test, women in the study (counselling) group showed statistically significantly greater knowledge and compliance of health promotion $(P<0.001)$ than women in the control group. Before the intervention, about half of the participants in each group had satisfactory knowledge with regard to nutrition, with exercise being the lowest. This indicates that knowledge comes with understanding. Understanding of the implications of not complying will enhance compliance.

However, formal education seems to enhance better understanding and compliance and acts "directly on compliance rates" (Pell et al 2013). Invariably, pregnant women with lower levels of formal education may less likely comply with health education nor understand the risks associated with non compliance. A study by Pell et al (2013) revealed that a woman's level of education plays an important role in compliance; secondary or tertiary education enables women to approach health staff on relatively equal terms, to pose questions and, to potentially seek care with lesser concern about any possible reprimands. This demonstrates understanding and likelihood of better compliance. Earlier, Okuno (2001) in his general studies found that pregnant women with higher educational level might have higher compliance. Also, Ojo (2004) asserted that level of education has significant influence on pregnant women antenatal attitude, as pregnant women with basic education usually manifest positive attitude. Implying that with higher level of formal education, pregnant women would have better understanding of health education with positive compliance but with little or no formal education they are less likely to comply.

\section{Age of pregnant women and compliance}

Some studies have shown that age of pregnant women was related to compliance (Pell et al 2013, Onyeneho et al 2016). Onyeneho et al study showed that being older had significant association with compliance among pregnant women, while Pell et al (2013) observed that older pregnant women, who were more accustomed to the pregnancy experience, were less concerned about receiving assistance in monitoring their pregnancy. Earlier, Lorenc \& Branthwaite (2003) and Benner (2002) had observed that advancing age affected compliance negatively. Furthermore, pregnant women tend be more forgetful as they advance in age, thus asserting that older pregnant women do not comply while younger pregnant women comply with health education. On the other hand, Lorenc \& Branthwaite 
(2003) argued that primigravidae's (supposedly younger pregnant women) lack of experience - in not realizing that they were pregnant or not disclosing their pregnancy, culminated in delayed initiation of ANC and affected compliance negatively. They further stated that some adolescents and unmarried younger women hide their pregnancies to avoid the social ramifications of pregnancy at their age, and mainly expulsion from school. All these culminate to delayed ANC initiation and ultimately non compliance even when initiated.

\section{Parity (number of children) of the pregnant women and compliance \\ Parity of more than four has been shown to} increase noncompliance while mothers with less than four show compliance to health education (Akah, Emeribe, and Edem 2013). These women seem to lack time to care for themselves because of being cumbered with the care of many children; also they feel that they have been through the ANC severally and therefore nothing new. Pell et al (2013) study showed that older multiparous women, particularly in Kenya and Malawi, visited the clinic towards the end of the second trimester; this is a pointer to delay in ANC initiation and non compliance. The researchers however argued, that multiparous women who had experienced previous health problems during pregnancy were likely to initiate ANC much earlier and also comply with health education.

Despite the benefits of health education, it is observed that some pregnant women attending antenatal clinic in University of Calabar Teaching Hospital come up with complications such as severe malaria in pregnancy, severe anaemia, ruptured uterus, preterm babies, congenital malaria, that may be associated with non use of their insecticide treated net; also some babies develop neural tube defects caused by lack of foliate which may be an indicator that mothers did not comply to health education given to them. Others come after much delay and exhaustion in labour at home; these complications are increasingly leading to increased maternal mortality and infant mortality rate. In Nigeria compliance of pregnant women to health education during ANC is not uniform within the State, LGA's or town. There are variations due to religious beliefs, ethnicity, socioeconomic and demographic strata. Despite these variations the negative effect of poor or non compliance cut across the various groups. Again very few studies had explored in detail pregnant women personal characteristics such as parity, age, level of education and time factor, and how these affect their compliance in this locality. These facts justify the need for regional studies that allow for more efficient action in regard to measures for intervention based on locality. This study was therefore undertaken to find out the individual factors associated with compliance to health education among pregnant women attending antenatal clinic in University of Calabar Teaching Hospital, Cross River State, Nigeria.

\section{Significance}

The findings of this study will help inform midwives of the need for continuous health education in terms of family planning as it affects women's age, number of children and women education. It will help inform policies targeted at compliance behaviours among pregnant women that seek antenatal services in CRS and Nigeria as a whole. This finding of this study will provide baseline data for future researches in the relevant topic

\section{Purpose}

To determine individual (personal characteristics) factors associated with compliance to health education by pregnant women in University of Calabar Teaching Hospital, Cross River State Nigeria.

\section{Research Questions}

- What is the knowledge level of pregnant women about health education (attending antenatal clinic in university of Calabar teaching Hospital, Calabar).

- What proportions of pregnant women comply with heath education (attending antenatal clinic in university of Calabar teaching Hospital, Calabar).

- What individual factors (personal characteristics) of pregnant women attending antenatal clinic in university of Calabar teaching Hospital, Calabar affect their compliance to health education

\section{Hypothesis}

There is no significant relationship between educational status and compliance to health education by pregnant women attending antenatal clinic in University of Calabar

\section{MATERIALS AND METHODS}

Design A cross sectional descriptive survey design was adopted for this study.

The study Area: The study area was cross river state, which is one the thirty six states of the Federal Republic of Nigeria. Cross River State have eighteen (18) local government areas with Calabar as the capital. Site: The study was carried out in UCTH using the antenatal clinic of the Hospital Calabar. UCTH is the only tertiary health institution in the state where women are attended to by specialized professionals and their complaint are addressed by SERVICOM. This site was chosen by the researchers because it is a referral and training centre for all cadres of health personnel

\section{Population and Sampling Technique}

The target population consisted of all pregnant women who attended ANC from May 2016 to November 2016 Totalling 140 from hospital records. Pregnant women choose any convenient day of their choice (From Monday to Friday) to attend ANC. The researchers choose to go to the clinic on Thursdays since it was one of the antenatal clinic days and was also convenient. 140 pregnant mothers attending ANC on Thursdays were accessible. Hundred (100\%) percent of the accessible population of pregnant mothers was used. Exclusion criteria included pregnant women who were sick and those who were not willing to participate

\section{Research Instrument}

A self structured questionnaire with content validity index of 0.71 was used. A measure of its stability over 
time was assessed using a test-retest procedure which yielded a reliability co- efficient of 0.79 after an interval of two weeks

\section{Data Analysis}

Data was analyzed using simple proportions, percentages, and chi-square $\left(x^{2}\right)$ at $p<0.05$.

\section{Ethical consideration}

Formal permission was obtained from the research ethical committee of the University of Calabar Teaching Hospital for the study and informed consent was gained from all subjects that participated in the study. Anonymity was guaranteed and maintained.

\section{RESULTS}

Table 1: Socio-Demographic Variables of respondents $n=140$

Variables

\section{AGE}

$15-19 y r s$

$20-24 y r s$

$25-29 y r s$

$30-34$ yrs

$35-39 y r s$

$40-44 y r s$

45 yrs and above

TOTAL

EDUCATIONAL STATUS

No formal education

First school leaving certificate.

SSCE'

BSc

TOTAL

OCCUPATIONAL STATUS

Civil servant.

Farming

Self employed

Schooling

Fulltime Housewife

TOTAL

MARITAL STATUS

Single

Married

Divorced

Separated

Total

Religion

Christianity

Islam

Other specify

Total

ETHNIC GROUP

Efik

Ibibio

Hausa

Igbo

Yoruba

Other Specify

Total

NO OF CHILDREN

1

2

3

4

5 and above

Total

\section{Frequency}

12

29

39

18

12

24

6

140

23

36

64

17

140

36

24

29

12

39

140

24

98

6

12

140

124

11

5

140

59

46

6

12

11

6

140

46

17

24

29

24

140
Percentage

8.6

20.7

27.9

12.9

8.6

17.1

4.3

100.0

16.4

25.7

45.7

12.2

100.0

25.7

17.1

20.7

8.6

27.9

100.0

17.1

70.0

4.3

8.6

100.0

88.6

7.9

3.6

100.0

42.1

32.9

4.3

8.6

7.9

4.3

100.0

32.9

12.1

17.1

20.7

17.1

100.0 
Majority of the respondents, $68(48.8 \%)$ were between the ages of 20-29 years, $30(25 \%)$ were aged 40-45, while only $12(8.6 \%)$ respondents were between ages $15-19$ years. Majority $98(70.0 \%)$ were married. Majority 117 had formal education whereas only 23
$(16.4 \%)$ respondents had no formal education. Majority $98(70.0 \%)$ were married. Most $63(45 \%)$ of the respondents had between 1-2 children, whereas 77 $(55 \%)$ had between 3 and above.

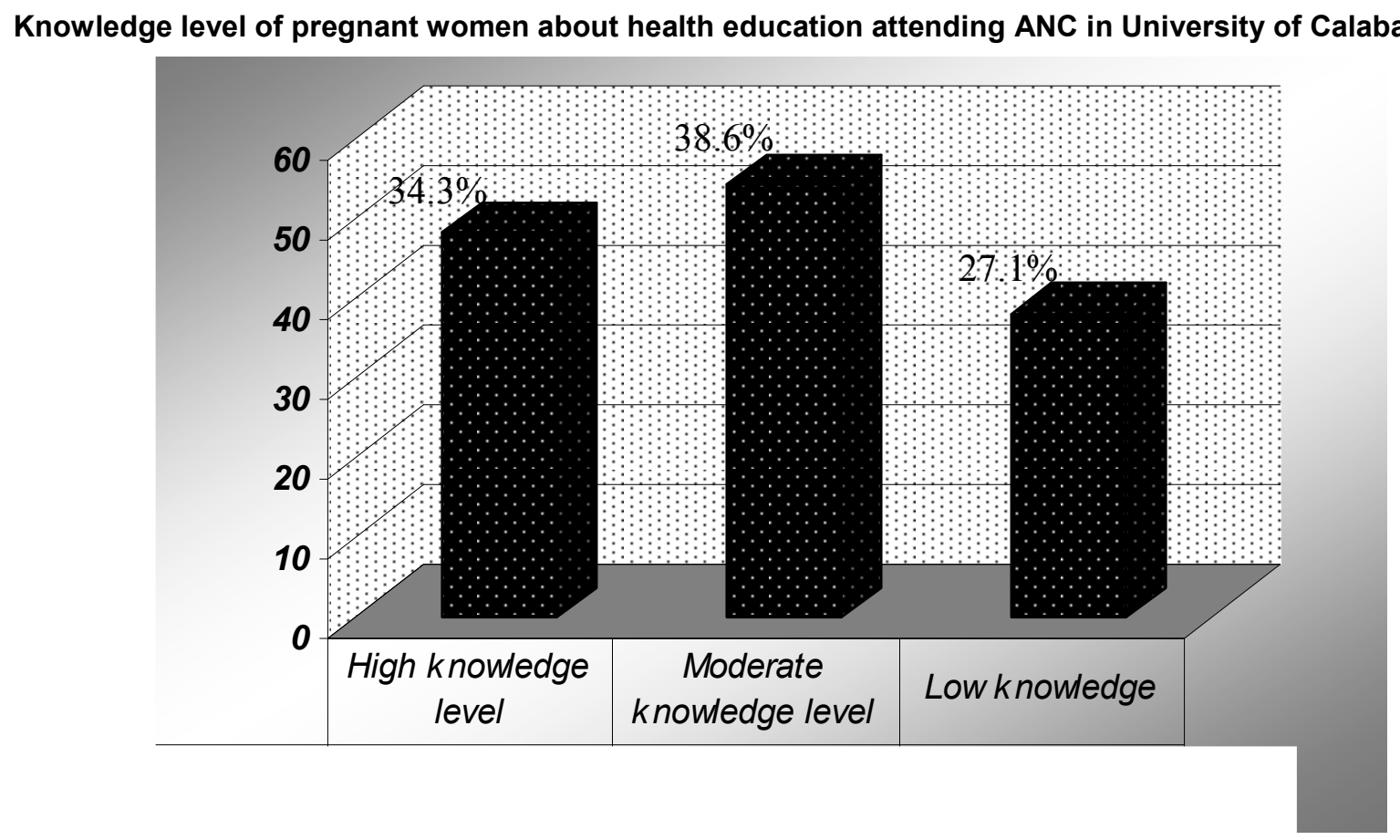

Fig 1: A bar chart showing the knowledge level of pregnant women about health education

Figure 1 revealed that most, 54 (38.6\%) respondents demonstrated moderate knowledge level of health education, $48(34.3 \%)$ had high knowledge while $38(27.1 \%)$ respondents had low knowledge of health education.
Proportion of pregnant women attending ANC in University of Calabar Teaching Hospital, who complied with health education

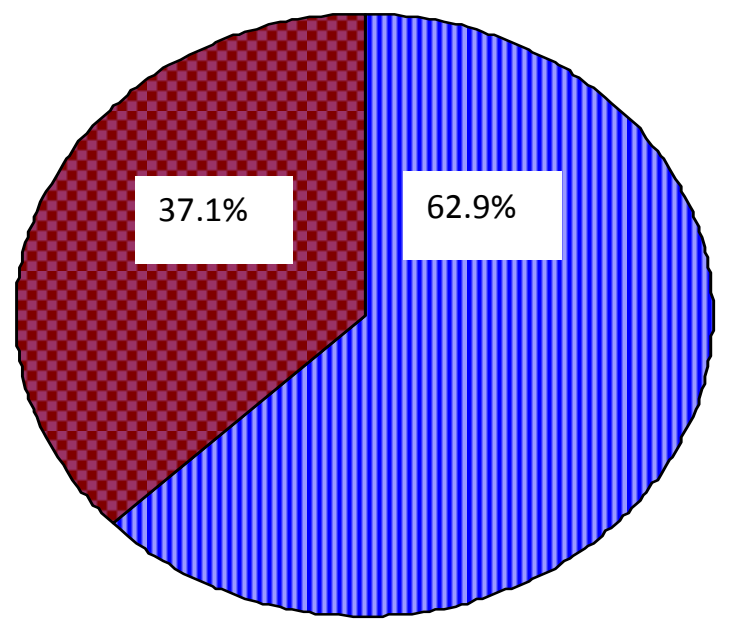

m Compliance to health advice

$\square$ Do not compliance to health advice

Fig. 2: A pie chart depicting the proportion of pregnant women who complied with health education and those who did not. 
Among the 140 respondents, 88 (62.9 \%) complied with health advice while $52 \quad(37.1 \%)$ respondents did not comply with health education
Individual factors (personal characteristics) that affect compliance to health education among pregnant women attending ANC in University of Calabar

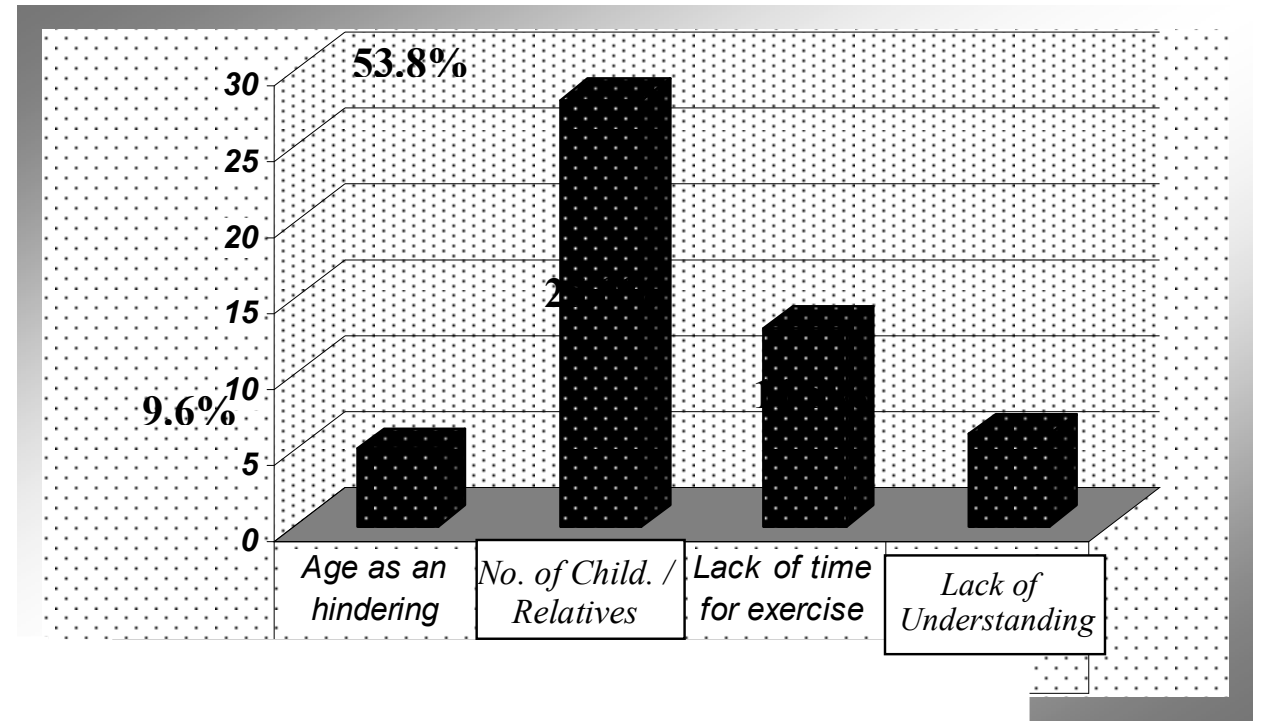

Fig. 3: A bar chart showing the individual factors that affect compliance to health education

28(53.8\%) respondents identified number of children (family responsibility) as the major individual factor that hindered compliance to health education, while lack of time for exercise hindered $13(25.0 \%)$ respondents, lack of understanding of some health education affected 6 $(11.5 \%)$ respondents and $5(9.6 \%)$ felt that their age were the hindering factor.

\subsection{TEST OF HYPOTHESIS}

Table 2: Chi-square analysis of the relationship between educational status and compliance to health education among pregnant women attending antenatal clinic in $\mathrm{UCTH}$

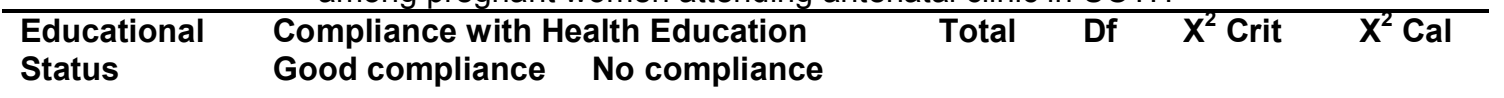

\begin{tabular}{lllllll}
\hline Formal & 80 & 37 & 117 & 3 & 7.815 & 31.56 \\
$\begin{array}{l}\text { Education } \\
\text { No Formal }\end{array}$ & 8 & 15 & & & & \\
$\begin{array}{l}\text { Education } \\
\text { Total }\end{array}$ & 88 & 52 & & & & \\
\hline
\end{tabular}

Significant at $0.05, \mathrm{df}=3, \mathrm{X}^{2}$ Calculated $=31.56, \mathrm{X}^{2}$ tabulated $=7.815$

From the chi-square analysis it could be seen that of the 88 pregnant women who complied with health education 80 had formal education while 8 did not. Also of the 52 pregnant women who did not comply with health education 37 had formal education while 15 did not

\section{SUMMARY OF RESULTS}

The findings of this study showed that out of the 140 respondents, 68(48.8\%) were between the ages of
(34.39\%), of respondents had moderate knowledge, $54(38.6 \%)$ had high knowledge, while $38(27.1 \%)$ had low knowledge about health education. Majority $117(83.6 \%)$ had various level of formal education only $23(16.4 \%)$ had no formal education. $88(62.9 \%)$ complied with health education while $52(37.1 \%)$ did not. The topmost individual factors that hindered compliance was number of children $28(53.8 \%)$, while lack of time for exercise hindered $13(25.0 \%)$ respondents, lack of understanding $6(11.5 \%)$ and age 5 ( $9.6 \%)$; Chi-square 
of educational and compliance to health education among pregnant women in UCTH.

\section{DISCUSSION}

The result indicating that majority, $102(72.45 \%)$ respondents have knowledge of ANC health education is encouraging considering the fact that knowledge is usually the first step towards the modification of desirable behaviour, also given that fact that a greater number of pregnant women 88 complied with health education. It is implied that the pregnant women's' knowledge of the importance of ANC services through health education enhanced their compliance. This result supports the findings of Mersal, Esmat and Khalil (2013) and Kumar (2000) who asserted that knowledge implied being aware and that before a pregnant woman would comply with health education she must been fully aware of the benefits of ANC services, benefits of compliance to health education and the complications that results from non compliance. The result also agrees with the findings of Ojong et al (2015) which revealed that majority of the pregnant women had good knowledge and subsequent favourable attitude towards focused antenatal care. This is a pointer that much is being done by health workers and midwives in UCTH, in providing adequate information to pregnant women who avail themselves of ANC services in the state given the fact that the studies were conducted in the same setting. Furthermore the study of Mersal, et al (2013) which showed statistically significant greater knowledge and compliance of health promotion after intervention with counselling also supports this result. Before their intervention, about half of the participants in each group had satisfactory knowledge with regard to nutrition but less than $50 \%$ had satisfactory knowledge regarding the other items, with exercise being the lowest. This indicates that knowledge comes through health education, counselling and understanding.

However, the number of pregnant women with low knowledge of health education 38 (27.1\%) and those who did not comply with health education was 52 $(37.1 \%)$, creates a gap which calls for concern given the fact that the only way to reduce maternal and neonatal mortality in Cross River State and Nigeria in general is through uptake of ANC services and compliance to health education which can be greatly achieved through creation of awareness and gaining of knowledge.

This study showed that parity $28(53.8 \%)$, and lack of time $(13(25 \%)$ were the highest individual factors that hindered compliance with health education by pregnant women. This is not surprising given the fact that $77(55 \%)$ of the respondents had given birth to 3 children and above, implying that the least among them was expecting her $4^{\text {th }}, 5^{\text {th }}$ Or $6^{\text {th }}$ baby (indicating multiparty). This finding is in agreement with that of Pell et al (2013) that showed that older multiparous women, visited the clinic towards the end of the second trimester; this is a pointer to delay in ANC initiation and ultimately non-compliance. Exception was the multiparous women who had experienced previous health problems during pregnancy who were likely to initiate ANC earlier (Pell et al (2013). The findings of this study buttresses the assertion of Katung, (2001), who opined that parity of more than four increases noncompliance while mothers with less than four show compliance to health education. The findings of Katung further supports this result, that multiparous women seem to lack time to attend to themselves because of being cumbered with the care of many children. These women feel that they have been through the ANC severally and therefore nothing new.

In this study, respondents' lack of understanding and age served as a minimal hindering factor to compliance. Considering the fact that majority of the respondents had formal education, it is not surprising therefore that lack of understanding did not constitute a worrisome hindrance because formal education enhances understanding. This finding is supported by Pell et al (2013), Ojo (2004) and Okuno (2001) who asserted that formal education enhances better understanding. Pell et al (2013) added that a woman's level of education plays an important role in compliance; education enables women to approach health staff on relatively equal terms, to pose questions and, to potentially seek care with lesser concern about any possible reprimands. This demonstrates understanding and likelihood of better compliance. The finding in relation to age is contrary to that of Onyenacho et al (2016) which showed that being older had significant association with compliance among pregnant women. Also, Lorenc \& Branthwaite (2003) and Benner (2002) have observed that advancing age affected compliance negatively. Pregnant women tend be more forgetful as they advance in age and this affects their compliance thus asserting that older pregnant women do not comply while younger pregnant women comply with health education.

Furthermore the result showed a significant relationship between educational status and compliance to health education among pregnant women attending antenatal clinic in UCTH; implying that the higher the educational status of a pregnant woman, the greater the compliance and vice versa. Indicating that with higher level of formal education, pregnant women found in this study had better understanding of health education with positive compliance. This finding agrees with that of Onyenecho, et al (2016) that showed that one key personal characteristics that had association with compliance was level of education. Also Pell et al (2013) study revealed that secondary or tertiary education enables women to approach health staff on relatively equal terms, to pose questions and, potentially, to seek care with lesser concern about any possible reprimands; this yields better compliance and vice versa. This result is also similar to that of Ukah et al 2013 that showed that level of education of pregnant mothers was significantly related with utilization of maternal/child health care services in Akpabuyo Local Government Area of Cross River State. The similarity in findings is not surprising given the fact that the two studies were conducted in the same state, and in nearby LGAs. Women in the state need to be encouraged to go to school as this will facilitate understanding, uptake and compliance to ANC services.

\section{CONCLUSION}

From the findings of this study it can be concluded that educational status and parity of pregnant women (attending ANC in UCTH) were major determinants of compliance to health education. 
RECOMMENDATIONS

- Government of Cross River State should fund free education for women.

- Clinical nurses/midwives should be intensified their efforts awareness creation and education for family planning

- Lastly the above variables that can influence compliance to health education should be considered in all interventions designed to improve compliance of pregnant women to health education during ANC

\section{REFERENCES}

Abosse, Z., Woldie, M and Ololo, S., 2010. Factors Influencing Antenatal Care Services Utilization in Hadiya Zone. Ethiop Journal Health Science 20, (2): 75- 82.

Abou-Zahr, C and Wardlaw, T., 2003. Antenatal care in developing countries: promises, achievements and missed opportunities: an analysis of trends, levels and differentials, 1990-2001. Geneva: World Health Organization.

Ademiju, S. A., 2007. Factors Affecting Drug Compliance in Tuberculosis at Jericho Chest Hospital, Unpublished (Msc Thesis). University of ljada.

Akah, L. A., Emeribe, V. C and Edem, E. M. A., 2013. Attitudinal indices as correlates to Maternal/child health care services utilization in Akpabuyo local government area of Cross river state Nigeria. International journal of medicine and medical science Research, 1, (5): 055-059.

Al-Ateeq, M. A and Al-Rusaiess, A. A., 2015. Health Education during antenatal Care: the need for more. International Journal for Women's Health. 7: $239-242$.

Ayandiran, E. O., 2008. Factors Influencing Compliances with Medical Regimen Among Chronic Renal Failure in Obafemi Awolowo University Teaching Hospital, Complex Ile Ife. Unpublished Msc thesis. O. A. U. Ife.

Becker, M. H and Mainan, L. A., 1974. Socio Behavioural Determinants of Compliance with Health and Medical Care Recommendation. Med care, 13, (2): $10-24$.

Benner, P., 2002. Demographic Variables: Compliant Behaviour in Pregnant Women. Philadelphia: JB Lippincott.

CIA World Fact book - on Maternal Mortality Rate: This page was last updated on October 8, 2016 Retrieved 11/06/17

Dairo, M. D and Owoyokun, K. E., 2010. Factors affecting Utilization of Antenatal Care Services in Ibadan, Nigeria. Epidemiology and Medical Statistics $12(1)$.
Dhange, P., Breeze, A. C. G and Kean, L. H., 2013. Routine antenatal management at the Booking clinic. Obstet Gynaecol Reprod Med., 23:45-52.

Dim, C. C and Onah, H. E., 2007. The prevalence of anaemia among pregnant women at booking in Enugu, South Eastern Nigeria. Med Gen Med., 9, (3): 11

Fraser, M., Cooper, M and Nolte, A., 2006. Myles Textbook for Midwives. (14 ${ }^{\text {th }}$ Ed.) Churchill Livingstone. London. New York.

Lorenc, I and Branthwaite, J., 2003. Socio demographic Factors Affecting Compliance. Toronto C. V. 11 OSBC.

National Population Commission (NPC) [Nigeria] and ICF International, Nigeria., 2014. Demographic and Health Survey 2013. Abuja and Rockville: NPC and ICF International.

Nwosu, E. O, Urama, N. E and Uruakpa, C., 2012. Determinants of Antenatal Care Services Utilisation In Nigeria. Developing Country Studies, 2(6).

Okuno, P., 2001. Factors Influencing Compliance in Pregnant Women. Modifying Health Behaviour. Maryland.

Olasemo, J. B., Balogun, M. O and Ajao, E. O., 2006. The Effects of Family Reinforcement in Compliance of Hypertensive Nigerians with Antihypertensive Therapy. Tropical Cardiology, 22, (2): 12- 22.

Onyeneho, N. G., Idemili-Aronu, N., Okoye, I., Ugwu, C and Iremeka, F. U., 2014. Compliance with intermittent Presumptive treatment and insecticide treated nets use during pregnancy in Enugu State, Nigeria. Maternal Child Health J; 18(5):11691175. doi: $10.1007 / \mathrm{s} 10995-013-1347-1$

Onyenecho, N. G., Orji, B. C., Okeibunor, J. C and Brieger, W. B., 2013. Characteristics of women who takes sulphadoxine-pyrimethamine twice in preventing malaria during pregnancy in Nigeria. Int J Gynaecol Obstet., 2013; 123(2):101-104. doi: 10.1016/j.ijgo..05.019.

Pell, C., Menaca, A., Were, F., Afrah, N. A., Chatio, S and Manda-Taylor, L. et al., 2013. Factors Affecting Antenatal Care Attendance, Results from qualitative studies in Ghana, Kenya and Malawi. PLoS 8, (1): e53747.

Simkhada, B., Teijlingen, E., Porter, $\mathrm{M}$ and Simkhada, P., 2008. Factors affecting the utilization of antenatal care in developing countries: systematic review of the literature. Journal of Advanced Nursing 61: $244-260$

UNFPA. Sub-Saharan Africa's maternal death rate down 41 per cent. 
http://africa.unfpa.org/public/cache/offonce/news /pid/10767; accessed on 15 December 2016.

United Nations Economic Commission for Africa., 2013. Report on progress in achieving the Millennium Development Goals in Africa. Addis Ababa: United Nations Economic Commission For Africa.

World Health Organization., 2002. Malaria in Africa: Roll Back Malaria Factsheet. Geneva. 